Ciência e Natura, Santa Maria, v. 36 Ed. Especial, 2014, p. 239-245

Revista do Centro de Ciências Naturais e Exatas - UFSM

ISSN impressa: 0100-8307 ISSN on-line: 2179-460X

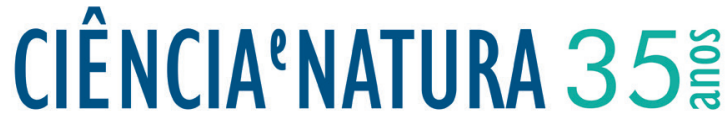

\section{Geografia e Paisagem}

\section{Geography and Landscape}

\author{
José Bueno Conti*1
}

${ }^{1}$ Universidade de São Paulo, São Paulo, Brasil

\begin{abstract}
Resumo
O artigo aborda a importância do conceito de paisagem para a geografia enquanto ciência que estuda as relações entre natureza e sociedade e o resultado desse processo interativo, expresso pela infinita variedade paisagística da superficie terrestre. Discute o conceito e analisa as afinidades da paisagem com o clima e a zonalidade. Analisa a iniciativa da USP ao introduzir no currículo de seu curso de bacharelado em geografia, nos anos sessenta, a disciplina "Fisiologia da Paisagem" e conclui fazendo uma avaliação da produção geográfica brasileira para o entendimento da paisagem.
\end{abstract}

Palavras-chave: Paisagem, natureza, sociedade, fisiologia.

\begin{abstract}
The article discusses the importance of the concept of landscape to geography science that studies the relationships between nature and society, the result of this interative process, expressed by the infinite variety of the landscapes surface. Discusses the concept and the affinities of the landscape and climatic zonality. It's analyzes the USP iniciative to introduce in the curriculum of their bachelor degree in geography in the 60's the discipline "Physiology of the landscape" and concludes with an evaluation of the production for the Brasilian geographical understanding of the landscape.
\end{abstract}

Keywords: Landscape, nature, society, physiology.

*zeconti@usp.br

Recebido: 19/03/2014 Aceito: 19/03/2014 


\section{Introdução}

$\mathrm{O}$ conhecimento científico é um conjunto de idéias estabelecidas e conectadas entre si, isto é, organizadas segundo uma ordem lógica. Baseia-se em teorias pré-formuladas e também conduz à construção de novas teorias ou paradigmas. A ciência é analítica, explicativa e propõe questionamentos.

No século XVIII Emanuel Kant propôs a classificação das ciências em duas categorias: as especulativas, apoiadas na razão, e as empíricas, fundamentadas na observação.Entre estas últimas estaria a geografia.

Pertencendo, ao mesmo tempo, ao domínio das ciências da terra e das ciências humanas, a geografia tem por objeto próprio a compreensão dos processos interativos entre natureza e sociedade, produzindo, como resultado, um sistema de relações e de arranjos espaciais que se expressam por unidades paisagísticas identificáveis em todas as escalas de grandeza. Faz uma interpretação dinâmica da realidade e se fundamenta sobre três princípios:os da localização, descrição e comparação.

A geografia trabalha com algumas noções básica tais como posição, orientação, lugar, região espaço, território zonalidade, paisagem, além de outros mais abstratos, como, por exemplo, ecúmeno. Todas são categorias de análise estudadas pela nossa ciência na a última - paisagem - aparece com especial destaque porque expressa a organização do espaço e todo seu aspecto multifacetado.

Na disciplina FLG 104 - Paisagem terrestre: da natureza à acultura, do empírico ao ideológico, credenciada no Programa de Pós-Graduação de Geografia Física da Faculdade de Filosofia, Letras e Ciências Humanas da USP, o docente responsável Prof. Adilson Avansi de Abreu, comenta na sua justificativa que a paisagem, em suas diferentes escalas de ocorrência, sempre foi considerada como objeto essencial da pesquisa geográfica.Lembra que Pierre Monbeig, a analisar os fatos geográficos de interesse para investigação, chama a atenção para a forma como eles se manifestam no complexo geográfico que "se exprime, antes de tudo, na paisagem, formada uma e indissoluvelmente pelos elementos naturais e pelo trabalho dos homens, é pois, a representação completa do complexo geográfico" e, ainda, na mesma página afirma: "A paisagem é um ponto de partida mas não um fim. Resulta do complexo geográfico sem confundir-se com ele" (MONBEIG, 1957, p. 11). O mesmo docente citado completa o pensamento de Monbeig, acrescentando que "o estudo da paisagem deve constituir a essência da pesquisa geográfica e o eixo estruturador de qualquer tema de investigação" .

A idéia de paisagem não se refere apenas ao que é observável pois o conhecimento dos fenômenos e processos menos visíveis são essenciais para se interpretá-la de forma cabal. Nessa linha Ab 'Saber afirma: "As paisagens têm sempre o caráter de herança de processos (fisiográficos e biológicos), de atuação antiga, remodelados e modificados por processos de atuação recente. Assim sendo, , as paisagens são uma herança, um patrimônio coletivos dos povos que, historicamente os modificaram ao longo do tempo e do espaço" (AB'SÁBER, 2003, p.9). Defendem o mesmo ponto de vista Milton Santos e Carl Sauer, sendo que este último sublinhava o papel da cultura ao longo do tempo.

A paisagem é, pois uma realidade viva e, nesse sentido seria adequado designá-la de tecido ecológico que recobre a superfície das terras emersas.

Desde Humboldt (1769-1859), que foi um estudioso da natureza em seu sentido mais genuíno, o tema está presente nas reflexões dos geógrafos. Com sua visão holística, enfatizando a vegetação como componente mais significativo da paisagem, preparou a introdução do conceito de landschaft muito praticado pela geografia alemã desde o século XIX e que se expressa por uma associação forte o local e seus habitantes. A maior parte dos estudiosos as escola germânica utiliza esse termo para designar o próprio objetivo da geografia $(\mathrm{BOESCH}$ e CAROL, 1968).

Na geografia francesa, poderíamos lembrar, entre outros nomes, o de Camille Vallaux, que, na primeira metade do século XX, afirmou: "A descrição lógica do espaço geográfico dirige-se, não do centro à periferia mas da periferia para o centro, de maneira que a paisagem, considerada pela Geografia, é uma paisagem de enquadramento. A paisagem geográfica, contudo, não é apenas de enquadramento; é também, ou deve ser, uma paisagem cinemática (VALLAUX, 1928, traduzido).

Conforme salienta Ary França em seu artigo Novas Diretrizes da Geografia Humana, a noção de paisagem encontra-se presente na obra de Maximilien Sorre Les Fondements de La Géographie Humaine (1947), como um complexo de imagens, incluindo as manifestações do espírito, isto é, os aspectos imateriais (FRANÇA, 1950).

\section{Considerações em torno do conceito}

Paisagem expressa uma idéia de síntese muito mais completa que a de região, território, espaço e lugar, categorias que também são amplamente estudadas pelos geógrafos.

Pierre George em seu livro Sociologie et Géographie deixa transparecer seu conceito de paisagem quando afirma: "Toda coletividade humana projeta-se sobe uma porção do espaço terrestre a qual, sob diversas formas, serve de suporte às suas atividades. Essa parcela do espaço comporta , de facto, uma estratificação de vários espaços, qualificados segundo a natureza de suas relações com as atividades e formas de existência dos grupos considerados (GEORGE, 1966, traduzido).

Jean Dresch, que deixou importante contribuição no campo da geomorfologia, lembra, em vários de seus trabalhos que o estudo da paisagem natural não será completa sem a análise da transformação ali realizada pela sociedade. 
Em 1968, o estudioso de Toulouse George Bertrand propôs um conceito bastante completo de paisagem: “É o resultado da combinação dinâmica, portanto instável, em uma determinada porção do espaço, de elementos físicos, biológicos e antrópicos, os quais, reagindo dialeticamente, uns sobre os outros fazem dela um conjunto indissociável em perpétua evolução". Segundo esse mesmo autor, a paisagem se expressaria pelo modelo teórico do geossistema, formado por três componentes: potencial ecológico, exploração biológica e ação antrópica (BERTRAND, 1968, traduzido).

No ano seguinte, Gabriel de Rougerie, da Universidade de Paris, em seu livro Géographie des Paysages afirma que nossa ciência é o estudo das paisagens, para cuja compreensão, seria indispensável decifrar todas as relações casuais, assim como as interações do complexo vivo que a constitui (ROUGERIE,1969).

Em 1972, Marcel Delpoux, da Universidade de Toulouse, daria um tratamento metodológico específico ao estudo da paisagem, assinalando que as mesmas seriam um entidade biofísica complexa, formada por dois constituintes: suporte, ou sejam, as características geológicas no sentido lato (orogênese, estratigrafia e litologia e cobertura, que seriam os parâmetros climáticos, biogeográficos e antrópicos (DELPOUX, 1972)

Citaríamos, ainda, o trabalho de Gabriel de Rougerie, em co-autoria com Nicolas Beroutchavili, este últmo da antiga República Soviética da Geórgia, que escreveram Géosystèmes et Paysages.Bilan et Méthodes onde analisam, de forma exaustiva, a emergência do tema, sua relevância para a Geografia atual, os métodos de estudo além de vários outros aspectos (ROUGERIE et BEROUTCHAVILI, 1991).

\section{Clima e paisagem}

Assim como o clima, a paisagem é produto de uma convergência de processos atmosféricos, geomorfológicos, hidrológicos e antrópicos.

O clima, abstrato enquanto categoria, não pode ser expresso em imagem mas aparece subjacente em qualquer paisagem da superfície terrestre, desempenhando papel relevante por meio da atuação de seus elementos tais como temperatura, umidade, ventos, etc. em diversas escalas de grandeza. Há uma forte sintonia entre clima e paisagem.

Os quentes e úmidos, por exemplo, manifestam exuberante biodiversidade, caudalosos cursos d'água e processos geomorfológicos muito ativos, ao contrário do que ocorre nas áreas frias onde predomina da criosfera e há pobre presença da biosfera. Ao contrário, onde se verifica carência de água no sistema natural caracterizamse pelo domínio de solo nu, areias, pedras e vegetação escassa constituída de cactáceas e arbustos de folhas pequenas, a fim de poupar a perda de água. As regiões de clima dito "temperado" ou de média latitude, para usar uma expressão mais apropriada, geograficamente, apresentam paisagens pouco agressivas e adaptadas à dinâmica sazonal onde ocorre a sucessão regular das estações do ano. Regiões próximas à linha de costa apresentam vegetação halófila típica de faixas transicionais entre continente e oceano, como, por exemplo, os mangues, que ocorrem dominantemente nas baixas latitudes As diferenças de altitude, a irregularidade e orientação do relevo também são fatores determinantes. Regiões deprimidas ou de fundos de vale tendem a ser mais secas que as elevadas, da mesma forma que as vertentes à barlavento ou sotavento são sempre contratantes paisagisticamente. Neste caso, o fator responsável é a maior ou menor exposição à radiação solar ou aos ventos com diferentes teores de umidade ou de sentido de fluxo, sendo os ascendentes (barlavento), estimuladores da condensação e da chuva e os descendentes (sotavento), inibidores do processo, provocando ressecamento da atmosfera na escala local. Nas altas montanhas, as paisagens se organizam em "andares", refletindo os fenômenos naturais característicos dos diferentes níveis.

\section{Zonalidade e paisagem}

Os filósofos da escola jônica (Grécia antiga, século VII a. C.) foram os que propuseram as primeiras explicações da natureza e do universo fundamentadas na razão e, nessa linha, admitiram, pioneiramente, a divisão da terra em zonas, isto é, em faixas de latitude, pois já tinham noção muito clara da esfericidade do planeta, idéias que seriam, mais tarde, referendadas, pelos estudiosos da escola de Alexandria. O fato é admirável porque, nessa época, ainda se desconhecia cerca de $90 \%$ superfície do mundo. Tal contribuição constitui um dos primeiros produtos da geografia como ciência racional.

Em nossos dias, o mestre De Martonne, em artigo apresentado nos Annales de janeiro de 1946, também sugeriria uma classificação das regiões do globo por faixas de latitude (MARTONNE, 1946).

Vários anos antes, o geomorfólogo alemão Albert Penck havia demonstrado a relação muito clara entre as formas do relevo e os cinturões climáticos do planeta.

Outro fato importante é que, desde fins do século XIX, William Morris Davis, geógrafo americano, havia oferecido ao exame dos estudiosos, um modelo de zoneamento dos fenômenos da natureza, assinalando a estreita dependência, com os climas, privilegiando, portanto, o princípio da zonalidade ou da Geografia Zonal .

A caracterização das grandes paisagens do planeta, dentro desse critério bem como as relações dialéticas entre a sociedade e o meio, tem sido o objetivo buscado pelos geógrafos e constitui tarefa complexa porque envolve, no mínimo três aspectos: a natureza, com todos os seus processos interativos, o intercâmbio de influências entre os fatos naturais e os produzidos pela sociedade, e, finalmente, a avaliação entre as condições pré-existentes 
do meio físico e as paisagens humanizadas resultantes da história, da cultura e das diferentes formas que a mesma natureza oferece.

A distribuição desigual da energia solar pela superfície do planeta, em função das diferenças de latitude, é o primeiro dado de macro-escala que deve ser considerado para se entender a zonalidade e, portanto, a distribuição das grandes paisagens, as quais, apresentam, dentro dos mesmos valores de latitude, uma evidente semelhança de aspectos.

A posição privilegiada do anel compreendido entre os $30^{\circ}$ de latitude, em ambos os hemisférios, faz concentrar aí grande quantidade de calor, dotando-a de um excedente energético muito significativo sobre o restante do planeta.

Esse acentuado desequilíbrio na distribuição da energia vai ser o ponto de partida para a interpretação das enormes diferenças paisagísticas assinaladas nas diferentes zonas da Terra. É claro que o fato está longe de ser simples, porque, na realidade, além da energia térmica, interferem inúmeros outros aspectos naturais, além dos efeitos da ação antrópica, especialmente em meso e micro-escalas.

A zonalidade que se observa na distribuição das grandes paisagens naturais e se manifesta, com relativa simetria em ambos os hemisférios é uma constatação importante do estudioso de geografia em macro-escala. Por sua vez, os grandes deslocamentos humanos que a história registra, especialmente os ocorridos no continente eurasiano até o início da Idade Moderna, embora impulsionados por variadíssimas motivações, fizeram-se dentro de uma mesma grande faixa zonal, não ultrapassando o limite dos $60^{\circ}$ ao norte (com a exceção dos vikings que, no século $X I$ atravessaram o Atlântico norte, da Escandinávia à Groenlândia, na latitude do Círculo Polar Ático) e o de $30^{\circ}$, ao sul.Estamos nos referindo às conhecidas migrações procedentes das estepes asiáticas em direção à Europa.

Os séculos XV e XVI, porém, conheceriam um ato novo: a migrações azonais, ou seja, a transferência de habitantes das médias latitudes para os trópicos, no bojo da expansão marítima promovida por portugueses e espanhóis e muito ampliada nos séculos seguintes pelo movimento colonialista, fruto do mercantilismo europeu. Como consequência, a Geografia das Paisagens ampliou-se até horizontes ilimitados.

\section{A "Fisiologia da Paisagem" como disci- plina curricular da USP}

Introduzida em 1968, no currículo do bacharelado em Geografia da então Faculdade de Filosofia, Ciências e Letras da USP, por inspiração do Prof. Aziz Nacib Ab 'Saber, a disciplina "Fisiologia da Paisagem"tinha como objetivo principal enfatizar a análise conjunta dos fatos geográficos, tomando a paisagem como unidade espacial de análise e sua integração no tempo e no espaço, sem descuidar dos processos genéticos de sua elaboração. Estimulava ao estudo de exemplos concretos. A idéia está sintetizada mo artigo Um conceito de geomorfologia serviço de pesquisas sobre o Quaternário (AB'SÁBER, 1969) em que a fisiologia da paisagem é apresentada como uma modalidade de pesquisa "em situações efetivamente dinâmicas" (op. cit. p.5), cuidando de compreender a paisagem globalmente por meio dos "processos morfoclimáticos e pedogenéticos atuais em sua plena atuação" (op. cit. p.2). A fisiologia da paisagem nada mais é do que uma interpretação abrangente do espaço geográfico enquanto realidade dinâmica e complexa. Em 1988 essa disciplina seria substituída por Teoria geográfica da paisagem, porém os objetivos e o conteúdo não sofreram mudança expressiva. Ao contrário, foi reforçada a reflexão sobre a pertinência da paisagem como objeto de investigação e o papel da ação antrópica em seu confronto com as forças da natureza.

Contudo, a orientação dos geógrafos no sentido proposto pelas disciplinas acima indicadas é mais antiga e precede, de vários anos, sua institucionalização nos quadros curriculares. Esta apenas consagrou uma prática demonstrada por estudos que encaravam a paisagem no seu dignifica global e ativo.

Um dos trabalhos mais conhecidos, nessa linha, é o do Prof. Hilgard O'Reilly Sternberg Enchentes e movimentos coletivos do solo no vale do Paraíba em dezembro de 1948. Influência da explotação destrutiva das terras, o qual, pelo seu pioneirismo, em termos de conteúdo e metodologia converter-se-ia numa das obras antológicas da geografia brasileira (STERNBERG, 1949). Tivemos oportunidade de fazer uma apreciação sobre o mesmo em artigo publicado na Revista do Departamento de Geografia da Faculdade de Filosofia, Letras e Ciências Humanas da USP (CONTI, 2001).

Entre outros que também poderiam ser citados está a tese de doutoramento da Prof ${ }^{\mathrm{a}}$ Olga Cruz A Serra do Mar e o litoral na área de Caraguatatuba abordando os catastróficos deslizamentos ocorridos na região de Caraguatatuba (SP) em março de 1967, produtos de uma excepcionalidade pluviométrica em encostas de equilíbrio precário, cuja fragilidade fora acentuada pela ação antrópica predatória, Houve muita destruição, com dezenas de mortos e desabrigados. Pela amplitude com que foi realizado o trabalho tornou-se uma das referências para os estudiosos da geomorfologia das encostas úmidas tropicais sendo mais um exemplo da orientação dos geógrafos na linha da fisiologia da paisagem (CRUZ, 1974).

\section{A produção geográfica brasileira e a pai- sagem}

Tentaremos analisar como foi abordado o tema da paisagem nas primeiras décadas da geografia brasileira, 
ou seja, desde a criação da Universidade de São Paulo (1934) até por volta de 1950, com ênfase para os estudos realizados em São Paulo.

Os franceses saíram na frente na análise de nossas paisagens, devendo-se ressaltar que, para a maior parte dos geógrafos da escola francesa, é o homem que prevalece sobre a natureza na criação e diferenciação (ou na definição da identidade) das paisagens, ou seja, a história e a cultura são fatores muito relevantes nesse processo. Daí a falta de características fortes (ou nitidez) nas paisagens dos países de ocupação recente, como o nosso, onde a economia é instável e o habitante ainda não estabeleceu uma sólida identidade com seu meio.

O pioneiro na interpretação das paisagens brasileiras do ponto de vista da geografia moderna foi Pierre Deffontaines que publicou, em 1935, o artigo Regiões e Paisagens do Estado de São Paulo. Esboço de uma divisão regional, uma primeira tentativa científica de divisão regional de nosso Estado onde começa por ressaltar essa fragilidade, ou seja a fraca identidade das paisagens em comparação com o que ele conhecida em seu país. Propôs uma divisão, não propriamente paisagística, mas regional baseada nas características naturais e seriam as seguintes: Litoral, Zona cristalina, Depressão periférica e Planalto arenítico-basáltico do oeste, reconhecendo duas ou três subdivisões em cada uma. Naquelas onde o homem ainda não deixou sua marca, Deffontaines afirma que "as paisagens não nasceram ainda; esperam o aparecimento dos homens e de seus trabalhos" (DEFFONTAINES, 1935).

O Prof. Pierre Monbeig, que o sucedeu, permaneceria 11 anos na USP (1935-1946), e também, como seu antecessor, chamaria a atenção, no caso brasileiro, para a falta de consciência de pays (ou ligação afetiva com o lugar) tão arraigado entre as populações francesas e européias em geral (MONBEIG, 1954). Esse mestre, contudo, soube interpretar o espaço geográfico brasileiro onde atuou (hoje correspondeste à Região Sudeste e ao Norte do Paraná) com admirável competência, como ficou demonstrado na vasta obra que deixou, ainda hoje, fonte de consulta e de proveito teórico, especialmente sua Tese de Doutorado, defendida na Universidade de Paris e publicada em 1952 - Pionniers et Planteurs de São Paulo. Essa pesquisa celebrizou-se, entre outros motivos, por ser o estudo de uma sociedade em movimento e do relacionamento desse dinamismo com o quadro físico sobre o qual se desenrolava, inovando, dessa forma o próprio conceito de espaço geográfico e, por extensão, da ; procura compreender e paisagem. (MONBEIG, 1952). Vários anos antes, em 1939, em conferência pronunciada na USP intitulada Paisagem, espelho de uma civilização afirmou: "A geografia não se contenta em descrever a paisagem concreta; procura reconstituir o mecanismo que conduz sua formação e evolução" (MONBEIG, apud SALGUEIRO, 2000). O mesmo autor voltaria ao tema em seu artigo Notas Relativas à Evolução das Paisagens Rurais no Estado de São Paulo, no qual historia a evolução da paisagem rural paulista, desde o período colonial, relacionando-a com a sucessão de ciclos econômicos e a interação com a diversidade de quadros naturais (MONBEIG, 1944).

Em 1946, a Prof ${ }^{\text {a }}$ Nice Lecocq Muller apresentaria tese de doutorado, feita sob orientação de Monbeig, intitulada Sítios e sitiantes do Estado de São Paulo onde também está presente uma reflexão sobre a paisagem. No capítulo IX de seu trabalho a autora faz uma comparação entre as diferentes paisagens criadas pelo sitiante: “Na frente de colonização a paisagem se apresenta como uma combinação de matas derrubadas, queimadas recentes (...) à medida que se regride para a retaguarda a paisagem é menos natural e mais cultural (...) finalmente, na retaguarda, chega-se a paisagens bem humanizadas, com ocupação do solo perfeitamente demarcada". No mesmo capítulo analisa o dinamismo desses diferentes tipos de paisagens, conforme vai ocorrendo a transformação do espaço e, ao longo de toda a tese, pode-se acompanhar o processo de elaboração das paisagens rurais do Estado de São Paulo (MULLER, 1951, p. 185).

Dois anos depois, a comunidade geográfica brasileira seria enriquecida com a tese de doutorado do Prof. de doutorado do Prof. Renato da Silveira Mendes, também da USP, Paisagens Culturais da Baixada Fluminense, orientada, inicialmente por Monbeig e, após a partida deste para a França,em 1946, por Pierre Gourou. Esse trabalho se tornaria antológico pela maneira inteligente como caracterizou e interpretou a diversidade paisagística das regiões litorâneas e sublitorâneas do Estado do Rio de Janeiro, produto, ao mesmo tempo, das condições de tropicalidade, das características da cultura, da economia e das relações de produção dominantes naquele momento. O grande valor do trabalho está na forma cuidadosa com que analisa a elaboração das paisagens a partir das características do meio físico e sua evolução ao longo da história demonstrando como a geografia, enquanto ciência que estudo o espaço transformado, é sempre produto do processo interativo entre sociedade e natureza. Ilustra a pesquisa com 93 fotos, documentação excepcionalmente rica para os padrões da época (MENDES, 1950).

A diretrizes estabelecidas por Monbeig, enfatizando a reflexão sobre o conceito de paisagem, produziram vários outros frutos notadamente na geografia paulista, como seria de se esperar.

Em 1950, a Prof ${ }^{\text {a }}$ Ely Goulart Pereira de Araújo publicou o artigo "Alguns aspectos da paisagem rural do município de Olímpia (SP), no qual estuda a rápida transformação da paisagem pioneira em uma região econômica e demograficamente estagnada, em apenas duas décadas. Mostra de forma clara que ali existiam, à época em que o estudo foi feito, duas paisagens, ambas criadas pela atividade humana, a de sudeste (do município), predominantemente agrícola, e a de noroeste, pastoril, refletindo, a autora, a postura da geografia francesa que interpreta a paisagem como resultado, 
antes de tudo, da ação transformadora do homem sobre a natureza (ARAÚJO, 1950).

Em 1952 registram-se duas contribuições dignas de nota: "Paisagens e problemas rurais da região de Santa Isabel", de Aziz Nacib Ab'Sáber e "As paisagens humanizadas da ilha de São Sebastião", de Ary França. Na primeira são mostradas as paisagens rurais das duas vertentes hidrográficas do município de Santa Isabel, a do Tietê e a do Paraíba ambas com feições tipicamente rurais, embora situadas a menos de $60 \mathrm{~km}$ da capital paulista, fruto da cultura de sua população historicamente vinculada às práticas agrícolas .Na segunda, o autor oferece um dos primeiros estudos das paisagens litorâneas do Estado de São Paulo, construídas por pescadores e caiçaras, onde aparecem as marcas da ocupação predatória que a caracteriza e constitui uma herança da cultura indígena.

Em 1967 Pasquale Petrone retoma o estudo pioneiro de Deffontaines, de 1935, publicando um trabalho com o mesmo título Regiões e Paisagens do Estado de São Paulo onde mostra que todas as áreas o Estado de São Paulo conheceram a elaboração de paisagens culturais resultantes da interação entre atividades humanas e condições naturais. Numa primeira aproximação e dentro desse critério destaca o fato de que o território de São Paulo é caracterizado por três grandes mosaicos paisagísticos que se conectam à terras subtropicais do Brasil Meridional, aos domínios tropicais das chapadas e campos cerrados do Brasil Central e aos conjuntos serranos e de "mares de morros" do Brasil de Sudeste. Por outro lado, assinala que "as paisagens do Planalto Ocidental caracterizam-se por serem as menos estáveis do Estado dado que são as de mais recente elaboração" (PETRONE, 1967, p. 63).

É interessante constatar que, um exame a coleção do Boletim Paulista de Geografia em seus primeiros cinco anos de circulação (1949-1954) com 18 números publicados (note-se a freqüência com que saía a Revista na época!), tinha uma seção designada de Fotogeografia, que reproduzia fotos, acompanhadas de comentários. Os textos nada mais eram do que interpretações de paisagens feitas segundo os princípios da melhor geografia. Um bom exemplo é o trabalho de João Dias da Silveira em suas 12 fotos retratando paisagens do Marrocos do tempo em que ainda era protetorado francês, a partir das quais o autor apresenta uma reflexão sobre a paisagem (SILVEIRA, 1952).

Em 1956, por ocasião do XVIII Congresso Internacional de Geografia do Rio de Janeiro, promovido pela União Geográfica Internacional (UGI), visitou nosso país o Prof. Pierre Deffontaines, que aqui havia estado em 1934, durante o primeiro ano de funcionamento do curso de Geografia e História na USP. Participando de excursão ao Centro-Oeste brasileiro, elaborou uma série de desenhos retratando paisagens do Pantanal e Chapada dos Guimarães, no antigo estado de Mato Grosso, as quais seriam publicadas, em primeira mão, pelo Boletim Paulista de Geografia, acompanhadas de comentários de Aroldo de Azevedo (AZEVEDO, 1956). Nesse particular Deffontaines seguiu o exemplo de Emmanuel De Martonne que, em sua obra, Traité de Géographie Physique apresenta vários desenhos e esboços com o objetivo de interpretar as paisagens, destacando seus aspectos físicos, como, por exemplo, a do vale glaciário de Lauterbrunnen, nos Alpes Suíços (MARTONNE, 1925, pág. 905, tomo 2). Entre nós, Carlos Augusto de Figueiredo Monteiro ofereceria importante contribuição iconográfica com desenhos bem elaborados e geograficamente interpretados de paisagens brasileiras sendo um dos melhores exemplos os blocos-diagramas e os esboços tomados no campo apresentados em seu trabalho seu trabalho sobre o Baixo São Francisco (MONTEIRO, 1962).

Em 1973 é publicada a tese de doutoramento do Prof. Adilson Avansi de Abreu Introdução ao Estudo das Paisagens do Médio Vale do Jaguari-Mirim (SP), onde, pela primeira vez é analisado o papel fundamental da geomorfologia na organização paisagística regional (ABREU, 1973).

\section{Considerações finais}

É importante salientar que todos esses trabalhos os quais, de uma forma ou de outra abordavam o tema da paisagem, foram elaborados numa época em que a geografia brasileira festava em suas primeira décadas, quase tudo estava por fazer e os recursos de pesquisa eram precários e escassos.

Nesse tempo a paisagem foi sempre tratada com destaque entre as várias linhas de investigação e concepções teóricas trabalhadas pela geografia. Nos últimos anos o tema vem sendo tratado com menos destaque, especialmente pelos praticantes da geografia humana, o que não é bom para a geografia, embora continue presente nos estudos da geografia da natureza.

O tratamento da paisagem como realidade integrada e dinâmica concorre para acentuar a unidade da geografia e diluir as fronteiras entre o social e o natural, robustecendo a singularidade de uma ciência que associa de forma inteligente fatos heterogêneos e diacrônicos e, por isso mesmo, não se confunde com nenhuma outra.

\section{Referências}

AB'SÁBER, A. N. - Paisagens e problemas rurais da região de Santa Isabel. São Paulo, Associação dos Geógrafos Brasileiros. Boletim Paulista de Geografia nº 10, p. 45-70, março de 1952.

- Um conceito de geomorfologia a serviço das pesquisas sobre o Quaternário - São Paulo, Universidade de São Paulo. Instituto de Geografia. 
Coleção “Geomorfologia” no 18, p. 1-14, 1969.

- Os domínios da natureza no Brasil.

Potencialidades paisagísticas. São Paulo, Ateliê

Editora, 2003, 159 p.

ARAÚJO, E. G. P. - Alguns aspectos da paisagem rural do município de Olímpia (SP). São Paulo. Associação dos Geógrafos Brasileiros. Boletim Paulista de Geografia no 5, p 12-22, julho de 1950.

BERTRAND, G. - Paysage et géographie physique globale. Equisse méthodologique. Toulouse, Revue Géographique des Pyrenées et du Sud-Ouest 39 (3), p. 249-272, 1968.

BOESCH, H. e CAROL, H. - Princípios do conceito de paisagem. Rio de Janeiro, Fundação IBGE, Boletim Geográfico ano 27, no 202, p. 26-29, 1968.

CONTI, J. B. - Resgatando a "Fisiologia da Paisagem". São Paulo, Universidade de São Paulo, Revista do Departamento de Geografia 14, p. 59-68, 2001.

CRUZ, O. - A Serra do Mar e o litoral na área de Caraguatatuba. Contribuição à geomorfologia tropical litorânea. São Paulo, Universidade de São Paulo. Instituto de Geografia, 1974, 181 p.

DEFFONTAINES, P. - Regiões e paisagens do Estado de são Paulo. Primeiro esboço de divisão regional. São Paulo, Associação dos Geógrafos Brasileiros, Geografia ano 1, no 2, p.117-169, 1935.

DELPOUX, M. - Ecosystème et paysages. Revue Géographique des Pyrenées et du Sud-Ouest, 43 (2), p. 157-174, 1972

FRANÇA, A - Novas diretrizes em Geografia Humana - São Paulo, Associão dos Geógrafos Brasileiros. Boletim Paulista de Geografia no 5, p. 3-11, julho de 1950.

- As paisagens humanizadas da ilha de São Sebastião. São Paulo, Associação dos Geógrafos Brasileiros, Boletim Paulista de Geografia no 10, p. 33-44, julho de 1952.

GEORGE, P. - Sociologie et Géographie. Paris, Presses Universitaires de France, 1966, 215 p. 1966.

MARTONNE, E. DE - Traité de Géographie Physique (tome second). Paris, Librairie Armand Colin, p. 905, 1951.

- Géographie zonale - Paris,

Armand Colin LVè année, nº 297, p. 1-18, 1946.
MENDES, R. S. - Paisagens culturais da Baixada Fluminense. São Paulo, Universidade de São Paulo, Boletim da Faculdade de Filosofia, Ciências e Letras no $^{\circ}$ CX (Geografia no 4), 171 p., 1950.

MONBEIG, P. - Paisagens rurais do Estado de São Paulo. Rio de Janeiro. IBGE, Boletim Geográfico nº 16, p. 428-430, 1944.

- Pionniers et planteurs de São Paulo.

Paris, Armand Colin Editeur, 1952, 376 p.

- Os problemas da divisão regional de São Paulo. São Paulo. Rio de Janeiro. IBGE, Aspectos geográficos da terra bandeirante, p181207, 1954.

- Novos estudos de geografia humana brasileira. São Paulo, Difusão Européia do Livro, p 5-25, 1957.

MULLER, N. L. - Sítios e sitiantes do Estado de São Paulo. São Paulo, Universidade de São Paulo, Faculdade de Filosofia, Ciências e Letras,Boletim 132, Geografia,1951, 216 p.

PETRONE, P. - Regiões e Paisagens do Estado de São Paulo. In "São Paulo, terra e povo. Porto Alegre, Editora Globo. P. 45-64, 1967.

ROUGERIE, G. - Géographie des paysages. Paris, Presses Universitaires de France (col "Que sais-je? $\left.\mathrm{n}^{\mathrm{o}} 1.362\right), 1969,126 \mathrm{p}$.

ROUGERIE, G. et BEROUTCHACHVILI, N. -

Géosystèmes et paysages. Bilan et methodes. Paris, Armand Colin Editeur, 1991, 302 p.

SALGUEIRO, H. A - Pierre Monbeig: a paisagem na ótica geográfica. In "Paisagem e Arte". Rio de Janeiro/São Paulo. Comitê Brasileiro de História da Arte/CNPq/FAPESP, p. 163-170, 2000.

SILVEIRA, J. D. da - Aspectos do Marrocos francês. Fotografias e comentários. São Paulo. Associação dos Geógrafos Brasileiros. Boletim Paulista de Geografia no 12, outubro de 1952, p. 65-68, 1952.

STERNBERG, H. O' - Enchentes e movimentos coletivos do solo no vale do Paraíba em dezembro de 1948. Influência da explotação destrutiva do solo. Rio de Janeiro, IBGE, Revista Brasileira de Geografia, vol. 11. no 2, p. 223-261, 1949.

VALLAUX, C. - Les sciences géographiques. Paris, Felix Alcan, 1929, 413 p. 